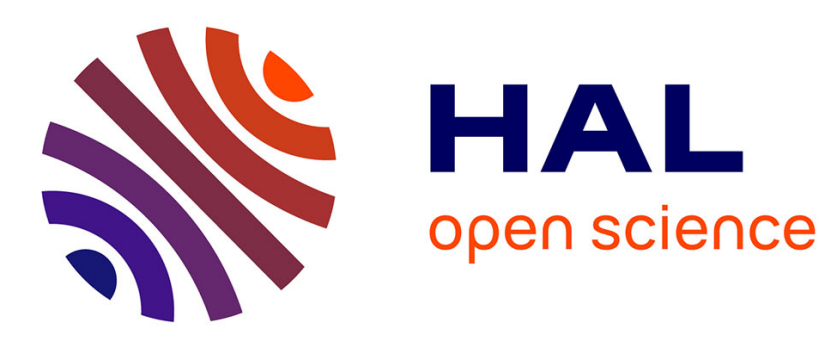

\title{
Radar Backscattering Coefficient Over Bare Soils at Ka-Band Close to Nadir Angle
}

\author{
Christophe Fatras, Pierre Borderies, Nicolas Baghdadi, Mehrez Zribi, \\ Mohammad El Hajj, Frédéric Frappart, Éric Mougin
}

\section{To cite this version:}

Christophe Fatras, Pierre Borderies, Nicolas Baghdadi, Mehrez Zribi, Mohammad El Hajj, et al.. Radar Backscattering Coefficient Over Bare Soils at Ka-Band Close to Nadir Angle. IEEE Geoscience and Remote Sensing Letters, 2016, 13 (9), p. 1290-1294. 10.1109/LGRS.2016.2582382 . hal-01414537

\section{HAL Id: hal-01414537 https://hal.science/hal-01414537}

Submitted on 16 May 2020

HAL is a multi-disciplinary open access archive for the deposit and dissemination of scientific research documents, whether they are published or not. The documents may come from teaching and research institutions in France or abroad, or from public or private research centers.
L'archive ouverte pluridisciplinaire HAL, est destinée au dépôt et à la diffusion de documents scientifiques de niveau recherche, publiés ou non, émanant des établissements d'enseignement et de recherche français ou étrangers, des laboratoires publics ou privés. 


\title{
Radar backscattering coefficient over bare soils at Ka-band close to nadir angle
}

\author{
Christophe Fatras, Pierre Borderies, Nicolas Baghdadi, Mehrez Zribi, Mohammad El Hajj, Frédéric \\ Frappart, Eric Mougin
}

\begin{abstract}
The behavior of the Ka-band backscattering coefficient at nadir and close-to-nadir angles for land applications is poorly documented. The measurements made during a ground-based campaign at Ka-band were performed at nadir and close-to-nadir angles over bare soils for different surface roughness and soil moisture conditions. The resulting backscattering levels exhibited a dynamic range of approximately $23 \mathrm{~dB}$ at nadir for soil moisture contents between 5 and $50 \%$ $\mathrm{m}^{3} / \mathrm{m}^{3}$ over both smooth and rough surfaces. These results were then compared to the Geometrical Optics (GO) and Millimeter MicroWave (MMW) models. Generally, GO finely fit the backscattering coefficients close to nadir, and MMW appeared to fit for larger incidence angles or rough surfaces. The results obtained in this study can address pre-launch science and engineering considerations for the interferometry-altimetry SWOT mission operating at Ka-band.
\end{abstract}

Index Terms - Radar, Ka-band, Bare soils, Soil moisture, Surface roughness.

\section{INTRODUCTION}

$\mathrm{R}$ adar altimetry measurements are commonly used to monitor water levels over land [1] and land surface properties, including surface soil moisture (SSM) estimation, mostly at $\mathrm{C}$ and $\mathrm{Ku}$ bands (e.g., [2],[3]). Since the launch of SARAL (Satellite with Argos and AltiKa) in 2013, which carried AltiKa, the first altimeter to operate at Ka-band

This paragraph of the first footnote will contain the date on which you submitted your paper for review. It will also contain support information, including sponsor and financial support acknowledgment. Christophe Fatras is supported by a CNES/ONERA PhD grant.

Christophe Fatras is with the Office National d'Etudes et de Recherches Aérospatiales (ONERA), 2 Avenue Édouard Belin, 31055 Toulouse Cedex 4, France, and also with the Université de Toulouse, OMP-GET, UM5563, CNRS/IRD/UPS, 14 Avenue Édouard Belin, 31400 Toulouse, France (e-mail: christophe.fatras@onera.fr).

Pierre Borderies is with the Office National d'Etudes et de Recherches Aérospatiales (ONERA), 2 Avenue Édouard Belin, 31055 Toulouse Cedex 4, France (e-mail: pierre.borderies@onera.fr).

Nicolas Baghdadi and Mohammad El Hajj are with the Institut national de recherche en sciences et technologies pour l'environnement et l'agriculture (IRSTEA), 500 rue JF Breton, 34093 Montpellier Cedex 05 (e-mail: nicolas.baghdadi@teledetection.fr; mohammad.el-hajj@teledetection.fr)

Mehrez Zribi is with the Centre d'études spatiales de la biosphere (CESBIO), 18 avenue, Édouard Belin, bpi 2801, 31401 Toulouse cedex 9, France (e-mail: mehrez.zribi@ird.fr).

Frédéric Frappart and Eric Mougin are with OMP-GET, UM5563, CNRS/IRD/UPS, 14 Avenue Édouard Belin, 31400 Toulouse, France (emails: frederic.frappart@get.obs-mip.fr, eric.mougin@get.obs-mip.fr).
(26-40 GHz), this frequency is also used to observe the Earth at nadir and near-nadir incidence angles [4]. It will be followed by the Ka-band Radar Interferometer (KaRIn) on board the NASA (U.S. National Aeronautics and Space Administration) and CNES (French space agency) Surface Water and Ocean Topography (SWOT) mission, to be launched in 2020 [5]. This mission will provide a global survey of Earth's ocean and inland water elevation in a 120$\mathrm{km}$-wide swath at an incidence ranging from $0.6^{\circ}$ to $4.5^{\circ}$. One of the major goals of hydrology is to inventory all terrestrial surface water bodies whose surface areas exceed $250 \mathrm{~m}^{2}$ (e.g., lakes, reservoirs, and wetlands) and rivers whose widths exceed $100 \mathrm{~m}$. This will be based on the ability to discriminate between land and inland waters using the backscattering coefficient.

The Ka band does not need another frequency band to correct the ionosphere delay. Due to its short wavelength $(\lambda$ $\sim 8 \mathrm{~mm}$ ), its use for interferometric purposes implies a reasonable baseline length compared to lower frequencies. Its main detrimental effect is its important attenuation and phase disturbances in the presence of water vapor.

Although the far-from-nadir radar response at $\mathrm{C}$ - and $\mathrm{Ku}$ bands over land is well documented, the near-nadir radar response of soils for the Ka band is poorly studied. This is primarily because the $\mathrm{Ka}$ band was not used for Earth observations until recently. In particular, the range of the radar response over agricultural areas with different SSM and roughness conditions is not well known for close-to-nadir incidence angles (SWOT pointing angles). Backscatter response measurements of bare soils were examined at 35 $\mathrm{GHz}$ (Ka-band) and $94 \mathrm{GHz}$ (millimeter band) on three soil surfaces with both dry and moderately wet soil conditions [6]. Unfortunately, the measurements were made at $20^{\circ}, 45^{\circ}$ and $70^{\circ}$ incidence angles, which are far from the nadir.

This paper, for altimetry purposes, focuses on the nadir and close-to-nadir angles, with measurements made at pointing angles of $0^{\circ}, 7^{\circ}$ and $25^{\circ}$ for six different surface roughness and SSM conditions. The measurement angles cover the nadir and close-to-nadir angles used on the SARAL/AltiKa $\left(0^{\circ}\right)$ and SWOT $\left(0.6^{\circ}\right.$ to $\left.4.5^{\circ}\right)$ missions. This campaign will lead to the first data set at Ka-band over bare soils for conditions similar to those of the SWOT acquisitions. Section II introduces the dataset and presents the radar measurements and the soil parameters (soil moisture and roughness measurement). In Section III, the results obtained are presented and analyzed. 
Section IV compares the backscattering coefficient measurements to scattering models.

\section{II.DATA SET DESCRIPTION AND METHODOLOGY}

\section{A. Radar backscattering measurements}

\section{1) Radar measurements and experimental setup}

The radar backscattering coefficients are calculated from near-field measurements made at Ka-band $(34.5 \mathrm{GHz})$ at VV polarization. The experimental setup consists of an offset parabolic reflector with a $60-\mathrm{cm}$ diameter that is fixed on a mast controlled by two step motors, which induce a rotation in both azimuth and incidence (Fig. 1). The near-field configuration is chosen to ensure a constant incidence angle on the ground illumination spot.

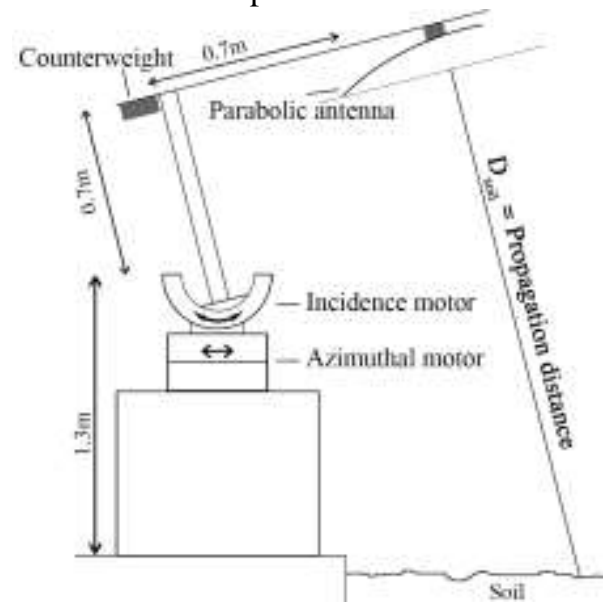

Fig. 1. Experimental setup. The azimuthal and incidence motors are indicated, along with the parabolic antenna, its counterweight, and the propagation distance of the electromagnetic field.

The antenna is connected to a millimeter-band Vector Network Analyzer (VNA, Anritsu 37269D model) through a flexible Radio Frequency (RF) cable. Both the motion controllers (Newport XPS) and the VNA are monitored with a personal computer.

The VNA emits and receives a frequency ramp of width $\Delta \mathrm{f}=1 \mathrm{GHz}$, with a center frequency of $34.5 \mathrm{GHz}$ and an IF filter of $10 \mathrm{kHz}$. The Fourier transform of the acquired complex data gives the impulse response, where the range resolution is $R=\frac{\mathrm{c}}{2 \Delta \mathrm{f}}=0.15 \mathrm{~m}$ and the unambiguous range is $\mathrm{d}=$ $\frac{\mathrm{c}}{2 \delta \mathrm{f}}=30.15 \mathrm{~m}$, where $\delta \mathrm{f}$ is the frequency step and $\Delta \mathrm{f}=\mathrm{N}_{\mathrm{f}} \delta \mathrm{f}$ $\left(N_{f}\right.$, the number of measurements in the frequency ramp=201).

The goal of this experiment is to estimate the backscattering coefficient $\sigma^{0}$ of a given soil through $\mathrm{N}$ successive and independent measurements. For each radar incidence angle $\theta_{i}$, 91 measurements $(\mathrm{N})$ were performed per angle for each plot by rotating the azimuthal motor with a step of $2^{\circ}$ over the ground, covering a $180^{\circ}$-wide area.

$\sigma^{0}$ corresponds to the incoherent field $E_{\text {inc }}$, which is extracted from the total field observed over $\mathrm{N}$ successive measurements $E_{t i}$ (i from 1 to $\mathrm{N}$ ) and the coherent field $E_{c}$ :

$$
E_{c}=\frac{\sum E_{t i}}{N}
$$

$$
\sigma^{0} \propto\left|E_{i n c}\right|^{2}=\left|\frac{\sqrt{\sum\left|\left(E_{t i}-E_{c}\right)^{2}\right|}}{N}\right|^{2}
$$

The precision obtained for $\sigma^{0}$ increases by $\frac{1}{\sqrt{N}}$.

\section{2) Data processing}

From a standalone measurement, we can calculate the impulse response in distance. Then, it can be manually filtered to extract only the ground backscattered signal that corresponds to the peak of interest. From the 91 independent measurements corresponding to the 91 azimuthal angles over each plot, we consequently extract the incoherent field using (1) and (2). To retrieve the expected backscattering coefficient $\sigma^{0}$, we use the center frequency value $(34.5 \mathrm{GHz})$. Calibration is performed using Eq. 3, which is valid if both the soil spot and the corner reflector are in the near field of the parabola and the latter is in the far field of the corner reflector:

with

$$
\sigma_{\text {calibrated }}^{0}=\frac{P_{r}}{P_{t r}}\left(\frac{D_{\text {soil }}}{D_{t r}}\right)^{2} \frac{\sigma_{t r}}{S_{\text {ant }}}
$$

- $\quad P_{r}$ as the measured incoherent field power

- $P_{t r}$ as the measured calibration trihedral corner reflector returned power

- $\quad D_{\text {soil }}$ as the propagation distance (see Fig. 1), which is a function of the azimuthal motor height and incidence angle of the system

- $\quad D_{t r}$ as the distance between the parabolic antenna and the corner reflector position during the measurement

- $\sigma_{t r}$ as the trihedral corner reflector theoretical radar cross-section of the edge length $a$, expressed in [7] as

$$
\sigma_{t r}=\frac{4 \pi a^{4}}{3 \lambda^{2}}(\text { with } a=7 \mathrm{~cm})
$$

- $\quad S_{\text {ant }}$ as the antenna surface projection over the ground, changing with the incidence angle $\theta_{i}$ and the antenna radius $R_{\text {ant }}$

\section{B. Ground measurements}

The radar measurements were taken over an agricultural area in the city of Montpellier, South of France. The soil is $35 \%$ clay and $15 \%$ sand. Three different SSM levels (dry, moderately wet and saturated) are considered, with both low and high roughness each time. The six different ground configurations, measured at $0^{\circ}, 7^{\circ}$ and $25^{\circ}$ of incidence, allow us to cover a wide range of soil conditions. A seventh ground configuration has been added by splitting the soft and wet ground surfaces into two parts $\left(\mathrm{N}^{\circ} 6\right.$ in Table 1$)$, as one part was mud ( $\mathrm{N}^{\circ} 7$, very smooth and very wet) and the other part exhibited the expected soil condition.

The ground plots covered by the measurements have an approximate surface area of $3.4 \mathrm{~m}^{2}, 4.3 \mathrm{~m}^{2}$ and $7.4 \mathrm{~m}^{2}$ for the $0^{\circ}, 7^{\circ}$ and $25^{\circ}$ incidence angles, respectively.

The bare soil was dry when the field campaign started $\left(\mathrm{SSM}<0.06 \mathrm{~m}^{3} / \mathrm{m}^{3}\right)$. The ground watering and mixing over a $10-\mathrm{cm}$ layer led to homogeneous, moderately wet and watersaturated surfaces. The surface roughness was manually changed by raking the ground coarsely or thinly. 


\section{1) Soil roughness parameters}

Measurements of soil roughness were carried out for each reference plot using a RIEGL VZ-400 terrestrial laser scanner mounted on a 2-m-high platform. The point density was approximately $1 \mathrm{pts} / \mathrm{mm}^{2}$. The laser provides scan data acquisition with 5-mm accuracy.

Different statistical approaches have been proposed for the description of roughness [8]. In the case of radar applications, the surface height is generally considered to be stationary and ergodic. For different soil samples, roughness estimation is conducted over profiles extracted from 3D surfaces. The roughness description of each profile is based on the computation of its surface height autocorrelation function. Two roughness parameters are extracted to describe the surface geometry: the standard deviation of the surface height (root mean square surface height, $(s)$ ), defining the vertical scale of the roughness; and the surface correlation length $(l)$, defined as the horizontal displacement for which the autocorrelation function of the profile decreases to $1 / \mathrm{e}$. As shown in Table 1, computations are performed in two directions (along the $\mathrm{X}$ - and $\mathrm{Y}$-axes) to consider the limited anisotropic effects due to tillage work. The results illustrated in Table 1 show large roughness dynamic range, with $s$ values ranging from 0.29 to $2.07 \mathrm{~cm}$ and $l$ ranging from $2.7 \mathrm{~cm}$ to 6.9 $\mathrm{cm}$. The considered grounds all have exponential autocorrelation functions, except for ground $\mathrm{N}^{\circ} 2$, which exhibits Gaussian behavior.

\section{2) Surface soil moisture}

Simultaneously with the radar measurements, ground measurements of soil moisture were obtained on six reference plots. Eight gravimetric soil moisture samples were collected for each reference plot over depths of $0-3 \mathrm{~cm}$. The volumetric soil moisture (SSM) was then obtained by multiplying the gravimetric soil moisture with the dry soil bulk density (eight measurements per reference plot). The volumetric soil moisture was then calculated for each reference plot using the mean of all of the soil moisture measurements collected on the reference plot. The soil moistures ranged from 0.045 to 0.501 $\mathrm{m}^{3} / \mathrm{m}^{3}$ (Table 1), with standard deviations between 0.023 and $0.074 \mathrm{~m}^{3} / \mathrm{m}^{3}$. This sampling depth matches the small penetration depths of microwave signals for small radar wavelengths (the first few centimeters, [8]).

\section{MEASUREMENT RESULTS}

The 21 backscattering coefficient measurements corresponding to the seven soils and the $0^{\circ}, 7^{\circ}$ and $25^{\circ}$ incidence angles are presented in Table 1 . The absolute error is $+/-1.4 \mathrm{~dB}$, as detailed in [10], with a relative error less than $0.5 \mathrm{~dB}$. The corresponding backscattering coefficients at the $0^{\circ}$ incidence angle range from $-1.8 \mathrm{~dB}$ (moderately wet and rough) to $21.4 \mathrm{~dB}$ (very smooth and very wet), thus presenting a maximal dynamic range of $\sim 23 \mathrm{~dB}$ between plots 4 and 7 . At $7^{\circ}$, we have a maximal dynamic range of $\sim 14 \mathrm{~dB}$, and at $25^{\circ}$, a maximal dynamic range of $\sim 8 \mathrm{~dB}$. At $0^{\circ}$ of incidence over plot $\mathrm{N}^{\circ} 7$, the backscattering coefficient of $21.4 \mathrm{~dB}$ is the result of water-saturated ground $\left(\sim 0.50 \mathrm{~m}^{3} / \mathrm{m}^{3}\right)$, which could correspond to riverbanks or bare soils after a strong rainfall.
This level is consistent with the backscattering value observed at the same frequency over water for small roughness [11].

TABLE 1

Summary of ground-truth measurements and radar observations (VV-polarization)

\begin{tabular}{|c|c|c|c|c|c|c|c|c|}
\hline \multirow{2}{*}{$\mathbf{N}^{\circ}$} & \multirow{2}{*}{ 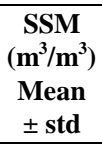 } & \multicolumn{2}{|c|}{$\begin{array}{l}\text { Roughness } \\
\text { s (cm) }\end{array}$} & \multicolumn{2}{|c|}{$\begin{array}{l}\text { Correlation } \\
\text { length } 1(\mathbf{c m})\end{array}$} & \multicolumn{3}{|c|}{$\begin{array}{c}\sigma^{0} \\
(\mathbf{d B})\end{array}$} \\
\hline & & $\begin{array}{c}\mathrm{X}- \\
\text { axis }\end{array}$ & $\begin{array}{l}\text { Y- } \\
\text { axis }\end{array}$ & $\begin{array}{c}\mathrm{X}- \\
\text { axis }\end{array}$ & $\begin{array}{c}\text { Y- } \\
\text { axis }\end{array}$ & $\begin{array}{c}\text { Angle } \\
0^{\circ}\end{array}$ & $\begin{array}{c}\text { Angle } \\
7^{\circ}\end{array}$ & $\begin{array}{c}\text { Angle } \\
25^{\circ}\end{array}$ \\
\hline 1 & $\begin{array}{c}0.045 \pm \\
0.039\end{array}$ & 0.29 & 0.4 & 3.09 & 6.87 & 8.9 & 3.6 & -1.4 \\
\hline 2 & $\begin{array}{c}0.057 \pm \\
0.074\end{array}$ & 1.13 & 1.36 & 4.74 & 6.23 & -0.9 & -1.8 & 0.3 \\
\hline 3 & $\begin{array}{c}0.213 \pm \\
0.035\end{array}$ & 0.44 & 0.54 & 2.67 & 4.78 & -1 & 0 & 0.1 \\
\hline 4 & $\begin{array}{c}0.181 \pm \\
0.05 \\
\end{array}$ & 1.52 & 1.81 & 4.09 & 5.65 & -1.8 & -3.5 & -0.3 \\
\hline 5 & $\begin{array}{c}0.501 \pm \\
0.023\end{array}$ & 0.69 & 0.81 & 3.10 & 4.39 & 7.4 & 5.1 & 6.2 \\
\hline 6 & $\begin{array}{c}0.414 \pm \\
0.024 \\
\end{array}$ & 1.84 & 2.07 & 3.53 & 5.40 & 0 & 0.5 & 1.9 \\
\hline 7 & $\begin{array}{c}0.501 \pm \\
0.023\end{array}$ & N/A & N/A & N/A & N/A & 21.4 & 10.5 & 5.9 \\
\hline
\end{tabular}

For dry soils $\left(\mathrm{N}^{\circ} 1-2\right), \sigma^{0}$ decreases by approximately $10 \mathrm{~dB}$ when the roughness increases from 0.3 to approximately 1.2 $\mathrm{cm}$ at nadir. This decrease becomes smaller with the incidence angle $\left(5.4 \mathrm{~dB}\right.$ at $7^{\circ}$ and $1.7 \mathrm{~dB}$ at $\left.25^{\circ}\right)$. For moderately wet soils ( $\left.\mathrm{N}^{\circ} 3-4\right), \sigma^{0}$ decreases by only $1 \mathrm{~dB}$ when the roughness increases from approximately 0.4 to $1.7 \mathrm{~cm}$ at nadir. This decrease becomes smaller for increased incidence angles $(3.5$ $\mathrm{dB}$ at $7^{\circ}$ and $0.4 \mathrm{~dB}$ at $25^{\circ}$ ). For wet soils ( $\left.\mathrm{N}^{\circ} 5-6\right), \sigma^{0}$ decreases by $7.4 \mathrm{~dB}$ when the roughness increases from approximately 0.7 to $2 \mathrm{~cm}$. This decrease is slightly less important with the incidence angle $\left(4.6 \mathrm{~dB}\right.$ at $7^{\circ}$ and $4.3 \mathrm{~dB}$ at $25^{\circ}$ ). Between measurements $\mathrm{N}^{\circ} 1$ and $\mathrm{N}^{\circ} 3$, for similar roughness parameters $(\sim 0.4 \mathrm{~cm})$, the increase in the soil moisture (from $\sim 0.05 \mathrm{~m}^{3} / \mathrm{m}^{3}$ to $\sim 0.21 \mathrm{~m}^{3} / \mathrm{m}^{3}$ ) induces a decrease in the $\sigma^{0}$ of $10 \mathrm{~dB}\left(3.6 \mathrm{~dB}\right.$ at $\left.7^{\circ}\right)$ and an increase of $1.5 \mathrm{~dB}$ at $25^{\circ}$. Between measurements $\mathrm{N}^{\circ} 4$ and $\mathrm{N}^{\circ} 6$, for similar roughness parameters $(\sim 1.8 \mathrm{~cm})$, the increase in the soil moisture (from $\sim 0.18 \mathrm{~m}^{3} / \mathrm{m}^{3}$ to $\sim 0.41 \mathrm{~m}^{3} / \mathrm{m}^{3}$ ) induces an increase in the $\sigma^{0}$ of $1.8 \mathrm{~dB}\left(4 \mathrm{~dB}\right.$ at $7^{\circ}$ and $2.2 \mathrm{~dB}$ at $\left.25^{\circ}\right)$.

Globally, we observe a decrease in or stable behavior of the backscattering coefficient with the incidence angle, which was expected. In particular, for large roughness, the backscattering coefficient is nearly constant over the observation range. The strong dependence of the backscattering coefficient with the incidence angle $\left(\mathrm{N}^{\circ} 1\right.$ and 7 , notably) may be explained by low roughness parameters, implying strong specular effects.

The results show how the combined effects of the various parameters impact the backscattering. Nevertheless, for the $0^{\circ}$ and $7^{\circ}$ incidence angles, one can verify that the lower the roughness is, the higher the $\sigma^{0}$ is for equivalent SSM (see $\mathrm{N}^{\circ}$ 1-2 and, alternately, $\mathrm{N}^{\circ} 5-6$ in Table 1). $\sigma^{0}$ thus seems to be more dependent on roughness parameters than on the soil moisture. Unfortunately, due to the important range of roughness parameters covered in this study, it was not possible to analyze the evolution of $\sigma^{0}$ with the SSM for similar roughnesses, but some trends in the behavior of $\sigma^{0}$ can be inferred. 

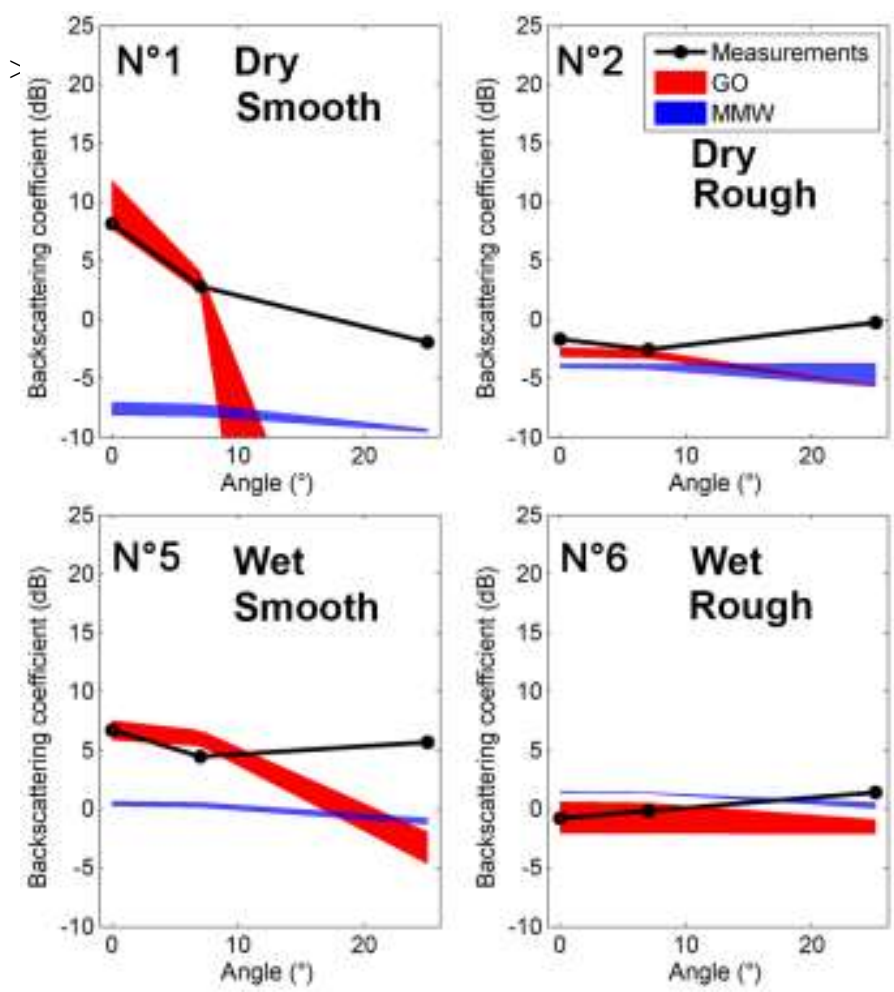
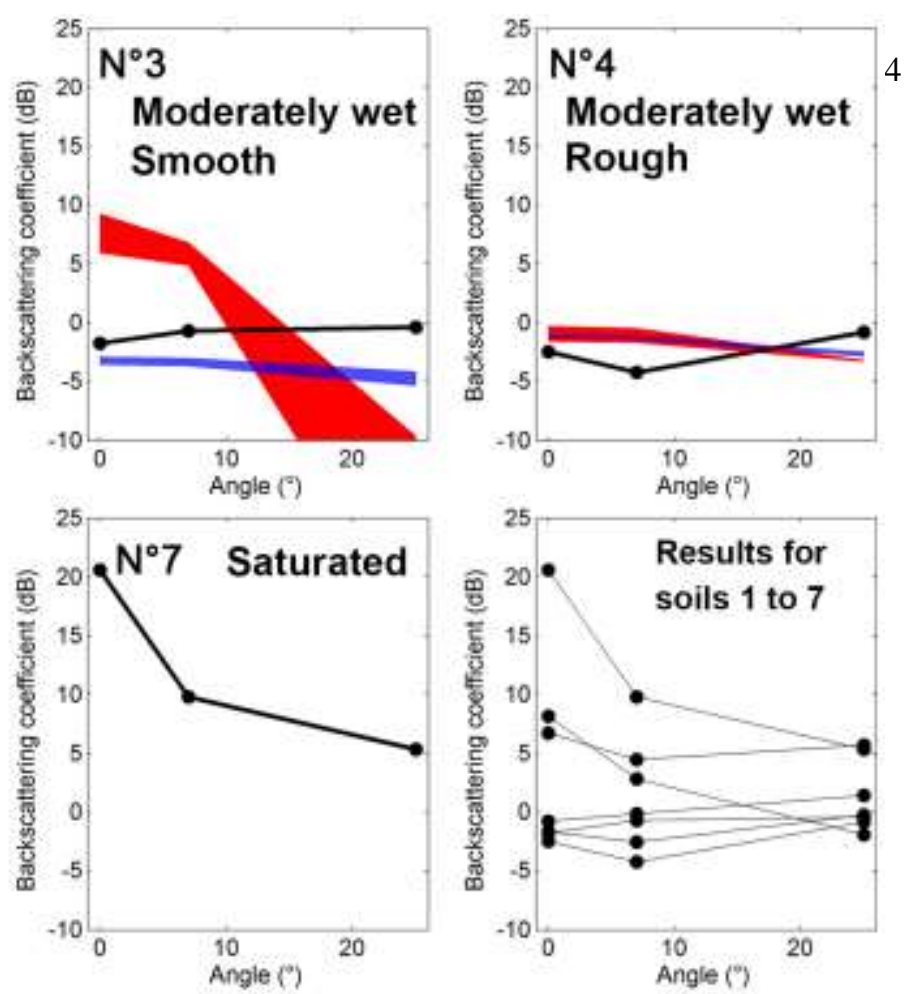

Fig. 2. Backscattering coefficients from measurements (in black) compared with GO (in red) and MMW (in blue). For the six first measurement surfaces ${ }^{\circ} 1-6$, the surface soil moisture (SSM) and roughness state are indicated (for specifications, see Table 1). The total measurements are also displayed.

\section{COMPARISON WITH SCATTERING MODELS}

\section{A. Scattering models}

In this section, the simulations from ground scattering models currently used at lower frequencies or higher incidence angles are compared with the previous experimental ones, both at Ka-band and at low incidence. According to the roughness measurements in our reference plots, the Geometric Optics (GO) model is in its validity domain [12] for all of them. Thereby, it was taken into consideration. Alternately, to the best of our knowledge, the only work presenting comparisons of experimental and simulated data for rough surfaces at Ka-band is [6]. It showed that the semi-empirical Millimeter MicroWave (MMW) model was relevant at high incidence angles (beyond $20^{\circ}$ ), so we found it interesting to investigate in our case.

\section{1) The Geometric Optics (GO) model}

The GO model, also called the Kirchhoff model for the stationary phase, is based on tangent plane approximation that considers the surface as a pattern of randomly oriented planes, each one locally tangent to the surface. We used the backscatter coefficient given by the stationary phase model.

\section{2) The MMW model}

The MMW model, for millimeter wavelengths, is defined in [6] as an adaptation of the model defined by Oh in [13]. The main advantage of this model is that it does not rest on the surface correlation length, the estimation of which is nontrivial [14]. It has not been developed for nadir-looking angles because it relies on the polarization ratio being beyond $10^{\circ}$. It gave satisfactory simulations compared to actual backscattering measurements, presented in [6] for $20^{\circ}, 45^{\circ}$ and $70^{\circ}$ incidence angles.

\section{B. Soil permittivity calculation}

The complex permittivity of soil is a key variable in the scattering models. Typical models (e.g., [15],[16],[17]) are limited to frequencies lower than Ka-band. For example, the widely used Dobson model [15] is valid up to $18 \mathrm{GHz}$. In [6], the determination of the permittivity discussed in [16] has been extended to Ka-band. This model, which relies on the mixture of soil and water dielectric permittivities with respect to the air-voids volume fraction of the soil, has been extended to the $\mathrm{Ka}$ band. The dielectric constant of water has been determined using [18] as a function of temperature $\left(20^{\circ} \mathrm{C}\right)$, salinity (here set to zero) and frequency. This model was then applied to Ka-band frequencies, and the calculated values were compared to [6] with good agreement.

\section{Comparison with measured data}

The two models described in the previous section have been applied to the first six measurement configurations. Due to the range of the roughness parameters for each type of soil, the range of the corresponding backscattering coefficient is displayed for each measurement configuration for both GO and MMW, as seen in Fig. 2. The differences between the measured and the mean backscattering coefficient values estimated from both GO and MMW are shown in Table 2.

GO simulations provide good agreement with measurements at $0^{\circ}$ and $7^{\circ}$ in most cases (measurements $\mathrm{N}^{\circ} 1-$ 2-5-6). For the case of $\mathrm{N}^{\circ} 4$, the agreement is good at nadir but poorer at $7^{\circ}$. The case of $\mathrm{N}^{\circ} 3$ is unique: the agreement is very poor for both angles. At a $25^{\circ}$ incidence angle, the agreement is fair for the rough soils (cases $\mathrm{N}^{\circ} 2-4-6$ ) but poor for the other ones. The MMW model is supposed to be valid beyond $20^{\circ}$. As a matter of fact, at $25^{\circ}$, in cases $N^{\circ} 2-4-6$, it presents fair agreement with the experimental results, and it 
can be seen that this agreement is also good for the other incidence angles $\left(0^{\circ}\right.$ and $\left.7^{\circ}\right)$, which was not expected. For the smooth soils, the agreement is poor (there is an underestimation) even at $25^{\circ}$. The GO simulated values are in accordance with the MMW model for the $\mathrm{N}^{\circ} 2$ and 4 measurements. At $25^{\circ}$, the GO values do not fit with the measurements.

\section{TABLE 2}

Absolutes differences (in $\mathrm{dB}$ ) between the measured and mean modeled backscattering coefficient values

\begin{tabular}{|c|c|c|c|c|c|c|}
\hline Angle & \multicolumn{2}{|c|}{$0^{\circ}$} & \multicolumn{2}{|c|}{$7^{\circ}$} & \multicolumn{2}{c|}{$25^{\circ}$} \\
\hline Model & GO & MMW & GO & MMW & GO & MMW \\
\hline $\mathrm{N}^{\circ} 1$ & 2.1 & 15.7 & 0.5 & 10.5 & 45.3 & 7.5 \\
\hline $\mathrm{N}^{\circ} 2$ & 1.1 & 2.3 & 0.4 & 1.5 & 5.4 & 4.3 \\
\hline $\mathrm{N}^{\circ} 3$ & 9.6 & 1.5 & 6.6 & 2.6 & 12.1 & 4.3 \\
\hline $\mathrm{N}^{\circ} 4$ & 1.6 & 1.3 & 3.2 & 3.0 & 2.4 & 1.8 \\
\hline $\mathrm{N}^{\circ} 5$ & 0.1 & 6.2 & 1.6 & 4.1 & 8.8 & 6.7 \\
\hline $\mathrm{N}^{\circ} 6$ & 0.3 & 2.2 & 0.4 & 1.5 & 2.9 & 1.1 \\
\hline
\end{tabular}

Measurement $\mathrm{N}^{\circ} 3$ must be considered apart from the others: it shows no correlation with GO, regardless of the incidence angle, and presents a fair agreement with MMW. Actually, the corresponding soil presents surface periodic features (the period between lines is approximately $2.5 \mathrm{~cm}$ ), which have been induced by the raking. These periodic effects are not taken into account by GO. The better behavior of MMW in this case might be explained by its lack of sensitivity to the horizontal variations, such as the correlation length used in the GO model. For such a surface, a specific model, such as the one in [19], should be used.

Globally, GO provides satisfactory simulated backscattering coefficient values for angles close to nadir, whereas MMW is correct for larger angles and for the rough soils.

\section{V.CONCLUDING REMARKS}

The global dynamic range of the backscattering coefficient at Ka-band reaches $23 \mathrm{~dB}$ at nadir, $14 \mathrm{~dB}$ at $7^{\circ}$ and $8 \mathrm{~dB}$ at $25^{\circ}$ for measurements that encompass large variations in roughness and moisture content. Some values measured over bare soils are similar to those measured over continental water surfaces, which is important in the context of the SWOT mission for water/soil discrimination.

The results show that the impact of roughness on the backscattering coefficient seems to prevail compared to the effect of soil moisture. A comparison with models has been carried out. First, a prior derivation of the complex permittivity at Ka-band proved to be satisfactory based on the global comparisons. For the $\mathrm{Ka}$ band and close-to-nadir angles, GO presents the best agreement for nearly all cases, whereas MMW is accurate for rough surfaces at all angles. Future prospects include the analysis of remote sensing data at Ka-band [20] using these results and models.

\section{ACKNOWLEDGEMENT}

We wish to thank Laurent Albrech and Alain Debreuil for their help during the field measurements.

\section{REFERENCES}

[1] F. Frappart, S. Calmant, M. Cauhopé, F. Seyler and A. Cazenave, "Preliminary results of ENVISAT RA-2-derived water levels validation over the Amazon basin," Remote Sensing of Environment, vol.100, no.2, pp. 252-264, 2006

[2] C. Fatras, F. Frappart, E. Mougin, M. Grippa, and P. Hiernaux, "Estimating surface soil moisture over Sahel using ENVISAT radar altimetry," Remote Sensing of Environment, 123(8), pp. 496-507, 2012.

[3] C. Fatras, F. Frappart, E. Mougin, P.-L. Frison, G. Faye, P. Borderies, L. Jarlan, "Spaceborne altimetry and scatterometry backscattering signatures at C- and Ku-band over West Africa," Remote Sensing of Environment, vol. 159, pp. 117-133, 2015.

[4] P. Vincent, N. Steunou, E. Caubet, L. Phalippou, L. Rey, E. Thouvenot, J. Verron, "AltiKa: a Ka-band altimetry payload and system for operational altimetry during the GMES period," Sensors, 6, pp.208-234.

[5] M. Durand, L-L. Fu, D. P. Lettenmaier, D. E. Alsdorf, E.L Rodriguez, D. Esteban-Fernandez, "The Surface Water and Ocean Topography Mission: Observing terrestrial surface water and oceanic submesoscale eddies," Proceedings of the IEEE, vol. 98, no. 5, pp. 766-779, 2010.

[6] Nashashibi, F. T. Ulaby, and K. Sarabandi, "Measurement and modeling of the millimeter-wave backscatter response of soil surfaces," IEEE Trans. Geosci. Remote sensing, vol. 34, no.2, pp. 561-572, Mar. 1996.

[7] G. T. Ruck, D. E. Barrick, W. D. Stuart, and C. K. Krichbaum, Radar Cross Section handbook, vol. I, Plenum Press, 1970.

[8] Zribi, M., Baghdadi, N., Holah, N., Fafin, O., and Guérin, C., 2005, "Evaluation of a rough soil surface description with ASAR-ENVISAT Radar Data", Remote sensing of environment, Vol. 95, 67-76.

[9] L. Bruckler, H. Wittono and P. Stengel, "Near surface moisture estimation from microwave measurements," Remote Sensing of Environment, vol. 26, pp. 101-121, 1988.

[10] O.Boisot, S. Pioch, C. Fatras, G. Caulliez, P. Borderies, A. Bringer, P. Borderies, "Ka-band backscattering from water surface at small incidence : a wind-wave tank study", Journal of geophysical research, 120(5), 2015.

[11] R. Fjørtoft, J.-M. Gaudin, N. Pourthié, J.-C. Lalaurie, A. Mallet, J.F. Nouvel, J. Martinot-Lagarde, H. Oriot, P. Borderies, C. Ruiz and S. Daniel, "KaRIn on SWOT: Characteristics of Near-Nadir Ka-Band Interferometric SAR Imagery," IEEE Trans. Geosci. Remote Sensing, vol. 52, pp. 2172-2185, Apr. 2014.

[12] F. T. Ulaby, R. K. Moore, and A. K. Fung, Microwave Remote Sensing, vol. II-III. Norwood, MA: Artech House, 1986.

[13] Y. Oh, K. Sarabandi, and F. T. Ulaby, "An empirical and an inversion technique for radar scattering from bare soil surfaces," IEEE Trans. Geosci. Remote Sensing, vol. 30, pp. 370-381, Mar. 1992.

[14] F. Mattia, M. W.J. Davidson, T. Le Toan, C. M. F. D'Haese, N. E. C. Verhoest, A.-M. Gatti, and M. Borgeaud, "A comparison between soil roughness statistics used in surface scattering models derived from mechanical and laser profilers," IEEE Trans. Geosci. Remote Sensing, vol. 41, pp. 1659-1671, Jul. 2003

[15] M. C. Dobson, F. T. Ulaby, M. T. Hallikainen, M. A. ElRayes, "Microwave Dielectric Behavior of Wet Soil - Part I: Empirical Models and Experimental Observations," IEEE Trans. Geosci. Remote Sensing, vol.Ge-23, pp. 25-34, Jan. 1985.

[16] M. C. Dobson, F. T. Ulaby, M. T. Hallikainen, M. A. ElRayes, "Microwave Dielectric Behavior of Wet Soil - Part II: Dielectric mixing models," IEEE Trans. Geosci. Remote Sensing, vol.Ge-23, pp. 35-46, Jan. 1985.

[17] V. L. Mironov, M. C. Dobson, V. H. Kaupp, S. A. Komarov, V. N. Kleschenko, "Generalized Refractive Mixing Dielectric Model for Moist Soils, » IEEE Trans. Geosci. Remote Sensing, vol. 42, pp. 773785, Apr. 2004.

[18] A. Strogyn, "Equations for Calculating the Dielectric Constant of Saline Water," IEEE Trans. Microwave theory and techniques, Aug. 1971.

[19] F. Mattia, "Coherent and incoherent scattering from tilted soil surfaces," Waves in Random and Complex Media, vol. 21, no.2, pp. 278-300, May 2011.

[20] F. Frappart, C. Fatras, E. Mougin, V. Marieu, A.T. Diepkilé, F. Blarel, P. Borderies, 2015. "Radar altimetry backscattering signatures at Ka, $\mathrm{Ku}, \mathrm{C}$, and S bands over West Africa," J. Phys Chem. Earth. Parts A/B/C, vol. 83-84, pp. 96-110, 2015. 